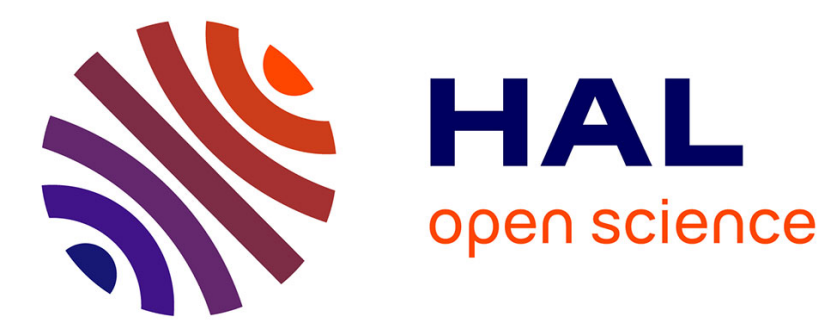

\title{
Flexible thermoelectric device based on TiS2(HA)x n-type nanocomposite printed on paper
}

Salim Ferhat, Christophe Domain, Julien Vidal, Didier Noël, Bernard Ratier, Bruno Lucas

\section{- To cite this version:}

Salim Ferhat, Christophe Domain, Julien Vidal, Didier Noël, Bernard Ratier, et al.. Flexible thermoelectric device based on TiS2(HA)x n-type nanocomposite printed on paper. Organic Electronics, 2019, 68, pp.256-263. 10.1016/j.orgel.2019.02.031 . hal-02062112

HAL Id: hal-02062112

https://hal.science/hal-02062112

Submitted on 22 Oct 2021

HAL is a multi-disciplinary open access archive for the deposit and dissemination of scientific research documents, whether they are published or not. The documents may come from teaching and research institutions in France or abroad, or from public or private research centers.
L'archive ouverte pluridisciplinaire HAL, est destinée au dépôt et à la diffusion de documents scientifiques de niveau recherche, publiés ou non, émanant des établissements d'enseignement et de recherche français ou étrangers, des laboratoires publics ou privés.

\section{(ㄷ)(1) $\$$}

Distributed under a Creative Commons Attribution - NonCommerciall 4.0 International 


\title{
Flexible thermoelectric device based on $\operatorname{TiS}_{2}(H A)_{x}$ n-type nanocomposite printed on paper.
}

\author{
Salim Ferhat ${ }^{\mathrm{a}}{ }^{\dagger}$, Christophe Domain $^{\mathrm{b}}$, Julien Vidal ${ }^{\mathrm{b}}$, Didier Noël ${ }^{\mathrm{b}}$, Bernard Ratier ${ }^{\mathrm{a}}$ and Bruno Lucas ${ }^{\mathrm{a}}$ \\ a. Univ. Limoges, CNRS, XLIM, UMR 7252, F-87000 Limoges, France. \\ b. EDF R\&D, Département Matériaux et Mécanique des Composants, avenue des Renardières - Ecuelles, \\ F-77818 Moret-sur-Loing cedex, France.
}

† Corresponding author: salim.ferhat@protonmail.com

\begin{abstract}
Flexible and lightweight printed thermoelectric devices are becoming increasingly attractive with the advent of ubiquitous sensing and within the context of an increasing energy demand and the associated environmental issues. In this study, flexible thermoelectric devices based on efficient solution-processed organic/hybrid thermoelectric materials have been successfully patterned. The $n-$ type component hexylammonium titanium disulfide $\left(\mathrm{TiS}_{2}(\mathrm{HA})_{x}\right)$ nanocomposite reaches a $\mathrm{ZT}$ of $0.08 \pm$ 0.06 at room temperature and was successfully printed on a flexible substrate using inkjet technology which yielded a functional device. The device operates in a near-ambient temperature range and retains its performance under mechanical bending, demonstrating thus the flexible properties of the device.
\end{abstract}

Keywords: printed electronics; thermoelectricity; nanocomposite semiconductors; device design; inkjet printing; sensors.

\section{Introduction}

Organic and hybrid thermoelectricity has attracted a great deal of attention in the past few years. The idea to recover electrical energy directly from low temperature waste heat with the help of organic/hybrid materials is becoming more interesting in the current context of increasing world energy consumption, well-known environmental problems, as well as resource management issues. Another increasingly important application of thermal energy harvesting could be in powering of connected devices and human-machine interfacing. Sophisticated networks of microsensors that are in permanent communication will need to be wirelessly powered and energetically autonomous, which is a challenge as conventional batteries cannot achieve that. A key possibility to solve this problem would be to harvest various ambient energy sources to power the multitude of sensors. Today, most commercially available sensors typically require at least milliwatts of power to operate, however some sensors can operate at powers as low as in the microwatt range [1]. Thermoelectric generators (TEGs) are specifically designed to transform heat into electrical energy - which is a process associated with the Seebeck effect. Thermoelectric devices can harvest ambient waste heat to power sensors, and, compared to conventional batteries, present several advantages like mechanical flexibility, light weight, little or no maintenance, long lifespan, wireless powering and more. In addition, a thermoelectric device could also be applied as a data acquisition sensor.

Traditionally, TEGs are fabricated from inorganic materials, namely $\mathrm{Bi}-\mathrm{Te}$ and $\mathrm{Pb}-\mathrm{Te}$ alloys, which are rare metals that are expensive, toxic and of costly processing. Therefore, organic and hybrid materials 
attracted a great deal of interest in recent years as an alternative to these inorganic compounds, as they present numerous advantages such as abundance and low cost, low thermal conductivity, environment-friendliness and convenient solution-based fabrication processes such as printing [2][6]. The costs of organic thermoelectric materials are typically several hundred times lower than those of $\mathrm{Bi}$-Te alloys [7]. Other interesting features of organic/hybrid materials are their easily tunable thermoelectric properties with various chemical treatments and suitable applications at low temperatures $\left(<250^{\circ} \mathrm{C}\right)$, which is interesting as the vast majority of inorganic compounds other than Bi-Te and P-Te alloys are not efficient at low temperatures [3]-[5], [7]-[10]. Thus, organic/hybrid materials can be a promising route as a basis of flexible large-area and low-cost thermoelectric generators.

The energy conversion efficiency of the material (input thermal energy to output electrical energy) is given by the factor of merit (ZT):

$$
\mathrm{ZT}=\mathrm{S}^{2} \sigma \mathrm{T} / \mathrm{K} \quad(\text { Eq. } 1)
$$

where $S\left(\mathrm{VK}^{-1}\right), \sigma\left(\mathrm{Sm}^{-1}\right), \mathrm{K}\left(\mathrm{Wm}^{-1} \mathrm{~K}^{-1}\right)$ and $\mathrm{T}(\mathrm{K})$ are respectively the Seebeck coefficient, electrical conductivity, thermal conductivity and temperature respectively. Organic and hybrid materials tend to have low thermal conductivities as they do not obey the Wiedemann-Franz law; thus, the correlation between $\sigma$ and $\mathrm{k}$ is usually weak [8], [9], [11]. Therefore, thermoelectric efficiency of organic and hybrid materials is often expressed by the Power Factor (PF): $\mathrm{PF}=\mathrm{S}^{2} \sigma\left(\mathrm{Wm}^{-1} \mathrm{~K}^{-2}\right)$, which is a convenient parameter to evaluate thermoelectric behaviour in case of low and slowly varying $\mathrm{K}$.

An efficient TEG design requires electrically balanced $n$-type and $p$-type materials as they are usually connected electrically in series and thermally in parallel. Although some interesting hybrid n-type materials have been proposed [12]-[14] with a maximum reported ZT near 0.28 [12], they are still behind their p-type counterparts performance-wise as a result of poor electron affinity leading to instability in ambient air and low electrical conductivity. Titanium disulfide $\left(\mathrm{TiS}_{2}\right)$ is a Van der Waals heterostructure composed of $2 \mathrm{D}$ thin films. Therefore, $\mathrm{TiS}_{2}$ has the capacity to host various materials, including organic components, in the interplanar space between 2D nanosheets. This ability of hosting various components has been investigated and exploited by Wan et al. (2015)[12] to improve the thermoelectric properties of $\mathrm{TiS}_{2}$. Precisely, a ZT of 0.28 at $373 \mathrm{~K}$ has been obtained by intercalating hexylammonium chloride. Later, the team suggested a more convenient synthesis method [15] with a lower ZT (near 0.1).

As for the p-type organic/hybrid materials, Kim et al. (2013) reported a PF of $470 \mu \mathrm{Wm}^{-1} \mathrm{~K}^{-2}$ and a ZT of 0.4 by immerging PEDOT:PSS films in Ethylene Glycol bath [16]. Later in 2016, Bae et al. (2016) demonstrated that similar performance could be achieved with Tellurium-PEDOT hybrid material chemically treated through immersion in sulfuric acid, obtaining thus a ZT of 0.39 [17]. Although there have been some successful efforts in developing fully printed organic and hybrid devices [18], [19], however, very few materials have been identified as easily adaptable to solution-based processes for easy and convenient device fabrication. A thermoelectric material must be transferable from laboratory scale processes to manufacturing processes that can be scalable to industrial mass production. Most of the reported thermoelectric materials are limited to laboratory-scale deposition techniques, such as spin coating or vacuum deposition, that do not easily transfer to mass-scale processing [20]. 
In this study, we develop a straightforward inkjet printing deposition process of a large Power Factor n-type hybrid nanocomposite hexylammonium titanium disulfide $\left(\mathrm{TiS}_{2}(\mathrm{HA})_{\mathrm{x}}\right)$ (suggested by Wan et al. (2015) [12]). Thus, flexible devices based on $\mathrm{TiS}_{2}(\mathrm{HA})_{x}$ as the n-type component and PEDOT:PSS polymer as the $p$-type component are patterned with ink jet printing on a flexible paper substrate. Furthermore, to the best of our knowledge, in this study the $\mathrm{TiS}_{2}(\mathrm{HA})_{x}$ nanocomposite is for the first time formulated into printable ink, and the results proved to be suitable for fabrication of functional organic thermoelectric generators (OTEGs) with inkjet printing technology.

\section{Experimental methods}

\section{1. $\mathrm{TiS}_{2}(\mathrm{HA})_{\times}$synthesis}

The synthesis process of $\mathrm{TiS}_{2}(\mathrm{HA})_{x}$ used in this study is inspired from Wan et al. (2016) [15]. Intercalation of hexylammonium from hexylammonium chloride (aqueous solution, $\geq 99.9 \%$ SigmaAldrich) in the interplanar space of $\mathrm{TiS}_{2}$ (99.9\%, Sigma-Aldrich) is done mechanically. The $\mathrm{TiS}_{2}$ powder is ground in a mortar and pestle simultaneously with a progressive addition of HA drops. The process can take some time, the rule of thumb is to finish when the resulting material becomes of metallicbrown colour, dries and easily detaches from the surface of the mortar. The resulting powder is then dispersed in N-Methylformamide (NMF, 99\% Sigma-Aldrich) dielectric solvent.

The mixture is then exfoliated in an ultrasonic bath. Ultrasonic forces can cause separation of layers of the van der Waals heterostructure which transforms nanoparticles into 2D nanosheets. The dispersion of $\mathrm{TiS}_{2}(\mathrm{HA})_{\mathrm{x}}$ is then centrifugated in order to separate the material from its excess dispersion medium NMF (2000 RPM for 30 minutes).

The resulting $\mathrm{TiS}_{2}(\mathrm{HA})_{\times}$dispersion in NMF is dropcasted on a glass substrate, which in turn is placed on a heating plate in an inert atmosphere $\left(\mathrm{N}_{2}\right)$. Thermal annealing enables the NMF evaporation and auto assembly of exfoliated nanoparticles into homogeneous films. In our experience, a thermal annealing below $100^{\circ} \mathrm{C}$ was not enough to evaporate the solvent, and above $115^{\circ} \mathrm{C}$ the deposited dispersion formed into clusters. The $100-115^{\circ} \mathrm{C}$ temperature range of the thermal annealing under an hour showed to be optimal for a homogeneous $\mathrm{TiS}_{2}(\mathrm{HA})_{x}$ film formation. The obtained samples are homogenous films of grey metallic or golden, upon light reflection, colour (figure 1).

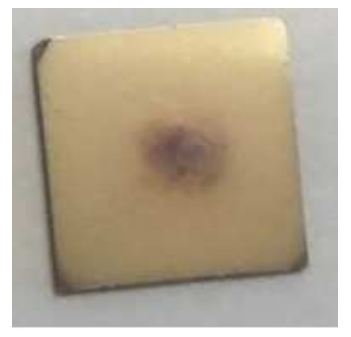

Figure 1. A $1.2 \times 1.2 \mathrm{~mm}^{2}$ sample of $\mathrm{TiS}_{2}(\mathrm{HA})_{\times}$film.

\subsection{Ink formulation and device fabrication}

PEDOT:PSS (PJET 700) is a PEDOT:PSS specifically formulated for inkjet printing by the fabricator (Heraeus) and was used in this study as the p-type component. Silver Ink (FI Ag-4101 of Novacentrix) was used for printing electrodes. $\mathrm{TiS}_{2}(\mathrm{HA})_{x}$ was formulated into printable ink in this study (see Results and discussions). The employed electrical pulse for drop generation is a standard pulse used for printing dielectric solvents and is integrated in the DIMATIX database (figure 2). The drop generation process is composed of 3 steps: at first (1) an applied negative electrical voltage causes a deformation 
of the piezoelectric crystal, whose expansion helps the liquid ink to fill the ink chamber. Subsequently, the electrical voltage is inversed, and the applied positive voltage causes the piezoelectric crystal to contract ("rise time" in (2)), thus ejecting the ink from the chamber through the nozzle. Finally, in (3) the electrical voltage is reversed again and the abruptly applied negative voltage cuts the ejected ink stream. The plateau between $7.936 \mu$ s and $11.52 \mu$ s "dwell time" timeframe decreases residual acoustic vibrations in the chamber. The wave is generated at a frequency of $5 \mathrm{kHz}$ and an amplitude of $26 \mathrm{~V}$. In the end, spherical drops with straight trajectories are obtained.

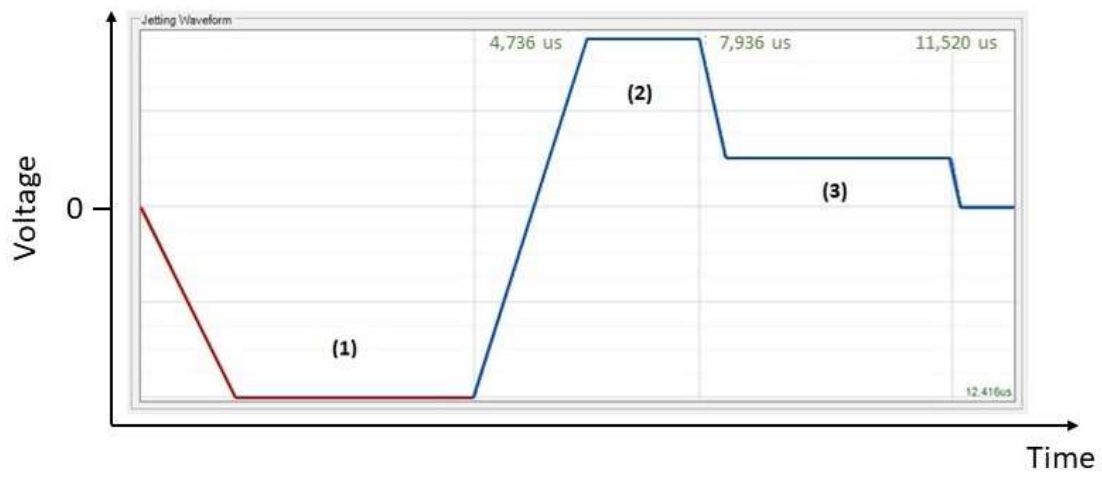

Figure 2. Electric pulse generating $\mathrm{TiS}_{2}\left[(\mathrm{HA})_{x}(\mathrm{NMF})_{\mathrm{y}}\right]$ drops

The device fabrication was realized in a sequential deposition of corresponding components. The production starts by printing the p-type component (PEDOT:PSS), followed by the printing of the $n$ type leg $\left.\left(\mathrm{TiS}_{2}(\mathrm{HA})_{\mathrm{x}}\right)\right)$ and ends with the deposition of silver electrodes on top of the thermoelectric legs (figure $3(a)$ ). An example of a printed OTEG is pictured on figure 3 (b).

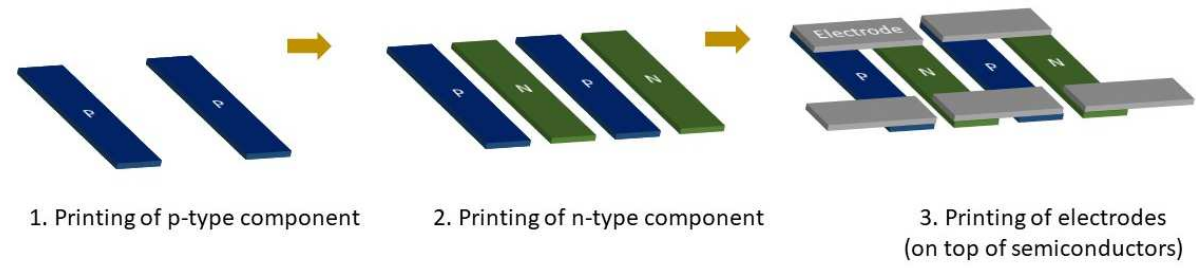

(a)

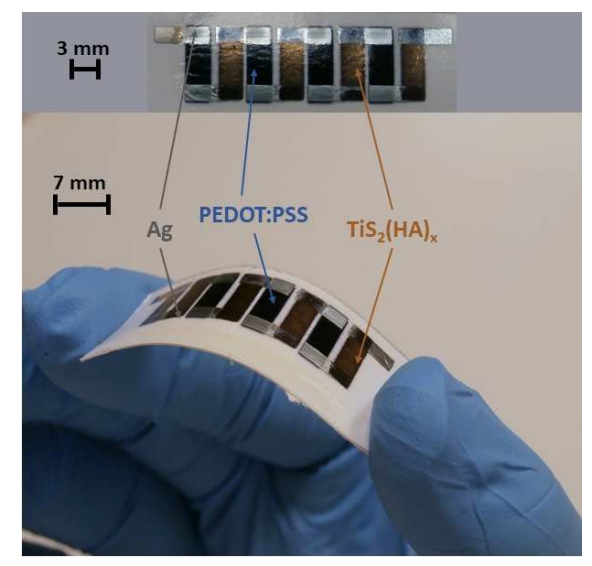

(b)

Figure 3. The printing deposition process of the device is sequential (a). Photography of a thermoelectric device printed on paper (b). 


\subsection{Characterization}

\subsubsection{Device characterization}

Thermoelectric performance of printed generators were characterized with an experimental setup shown in figure 4. In order to apply heat, the generator printed on flexible paper substrate was wrapped around a heated ceramic cylindrical piece (Boron Nitride). A thermal conductive paste was applied on the bottom electrodes to ensure good thermal contact between the heated piece and the electrodes. A temperature gradient was produced by heating the ceramic piece and thus heat was applied on bottom electrodes of the rolled generator. The heat source is a Peltier module which is connected to a temperature controller (Thorlabs TC200); the cold side is exposed to the ambient temperature and, therefore, $T_{C}=25^{\circ} \mathrm{C}$. The applied heat was programmed at $T_{H}=45^{\circ} \mathrm{C}$ to obtain a $\Delta \mathrm{T}$ of $20 \mathrm{~K}$.
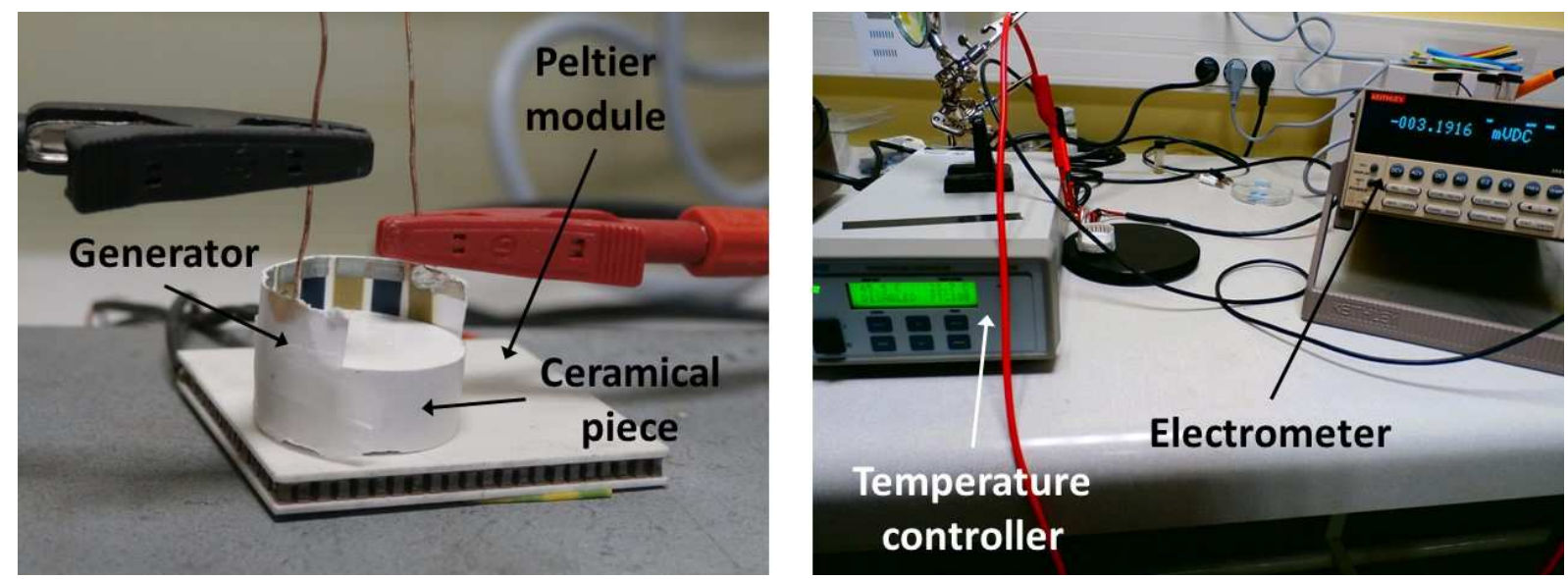

Figure 4. Experimental setup for the characterization of thermoelectric devices.

Electrical parameters of the generators such as the internal resistance $\left(R_{i}\right)$, open circuit voltage $\left(V_{o c}\right)$, short circuit current $\left(\mathrm{I}_{\mathrm{sc}}\right)$ and electric power output $\left(\mathrm{P}_{\max }\right)$ were measured with current-voltage $\mathrm{I}(\mathrm{V})$ profiling of the devices. Thermoelectric devices, with heat applied, are subjected to a voltage injection, which, in turn, produces an electrical current (measured with an electrometer (Keithley 2001)); analyzing the I(V) profile gives access to necessary parameters produced by thermoelectric generators $\left(\mathrm{V}_{\mathrm{oc}}, \mathrm{I}_{\mathrm{Sc}}, \mathrm{R}_{\mathrm{i}}\right.$, and $\left.\mathrm{P}_{\max }\right)$.

\subsubsection{Films characterization}

Electrical conductivity was measured with the classic four-point probe technique in air at room temperature. Thermopower measurements were carried out by placing two voltage probes equipped with heating points (heating up to $\Delta \mathrm{T}=9 \mathrm{~K}$ ) and thermocouples directly on thin films. The probes are connected to a Keithley 617 electrometer. The 3-omega method was used to measure the thermal conductivity.

X-ray diffraction analyses were carried out with a SIEMENS D5000 (Bruker) using Cu Ka radiation (wavelength $=0.15418 \mathrm{~nm}$ ). Sample thickness measurements were carried out with a Bruker Dektak XT profilometer. 


\section{Results and discussion}

\subsection{Intercalation process of $\mathrm{HA}$ into $\mathrm{TiS}_{2}$}

The intercalation of $\mathrm{HA}$ organic compound into $\mathrm{TiS}_{2}$ nanolayers enables mechanical flexibility of the $\mathrm{TiS}_{2}(\mathrm{HA})_{\times}$superlattice, which is a mandatory property a material must have in order to obtain thin flexible devices; in addition, the organic compound lowers the thermal conductivity of the hybrid material [12]. Figure 5 shows $\mathrm{X}$-ray spectrum of $\mathrm{TiS}_{2}$ powder and $\mathrm{TiS}_{2}(\mathrm{HA})_{x}$ films (with a molar ratio of 1:4 (TiS $2: \mathrm{HA})$ ). First, we can observe the crystalline nature of $\mathrm{TiS}_{2}$ powder, which is of hexagonal structure. The particularly interesting intensity peaks are (001), (002) and (003) as they characterize the interplanar distance between nanosheets of $\mathrm{TiS}_{2}$. Thus, considering their respective shift, we can deduce the distance variation between plans of $\mathrm{TiS}_{2}$ before and after the intercalation of $\mathrm{HA}$, and verify the intercalation process. The (001) peak of pristine $\mathrm{TiS}_{2}$ is situated at $2 \theta=15.55^{\circ}$ and is equivalent to an interplanar distance of about $5.7 \AA$. After grinding the $\mathrm{TiS}_{2}$ powder with $\mathrm{HA}$, the $(00 /)$ type peaks are found to shift to lower angles: the (001) peak, for instance, is shifted to $2 \theta$ values lower than $10^{\circ}$ (the $X$-ray diagrams are initialized at $\left.10^{\circ}\right)$. Using the (002) peak as the main indicator, we can see that after the intercalation the (002) peak shifts from $31^{\circ}$ to $17^{\circ}$, which is equivalent to an interplanar distance of $5.7 \AA$ and $10.4 \AA$ respectively before and after intercalation of HA. Such an increase in interplanar distance confirms the successful mechanical intercalation of $\mathrm{HA}$ molecules into $\mathrm{TiS}_{2}$.

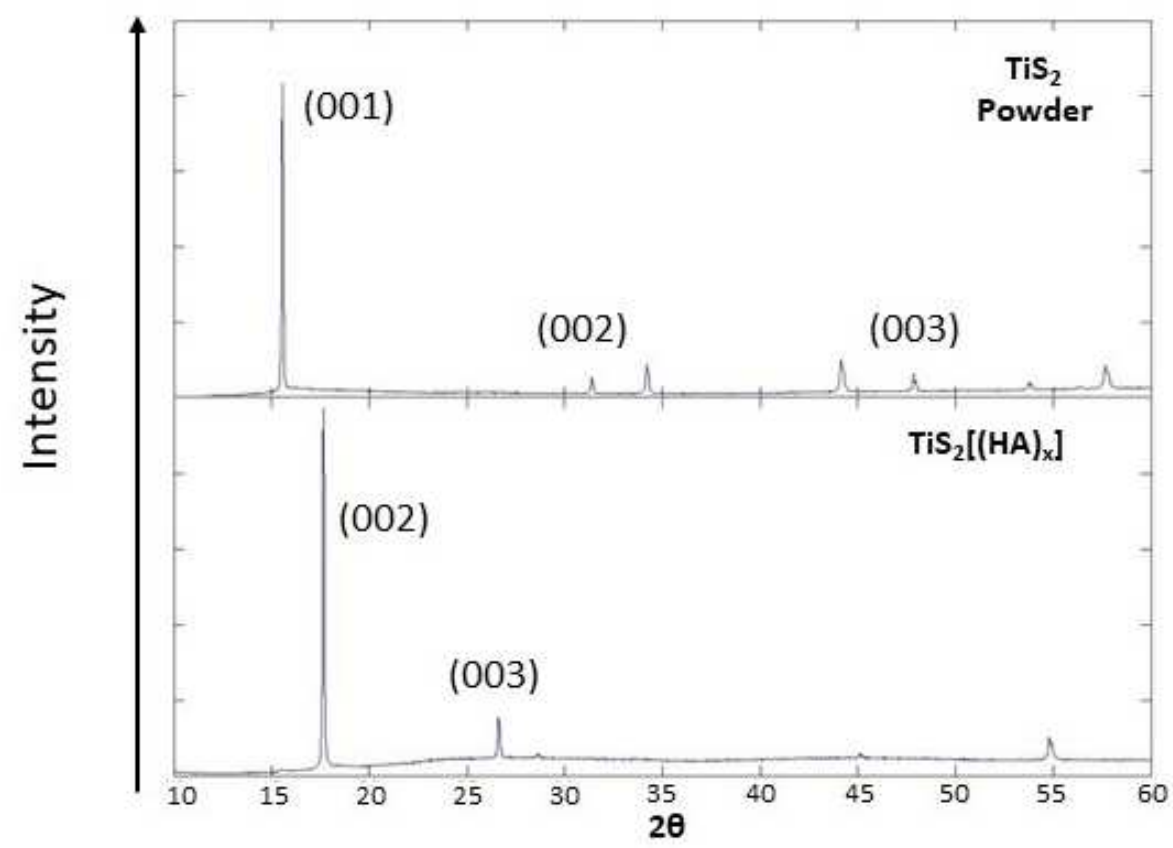

Figure 5. X-ray diffraction spectrum of $\mathrm{TiS}_{2}$ powder and $\mathrm{TiS}_{2}(\mathrm{HA})_{x}$ films (TiS $: \mathrm{HA}$ molar ratio of 1:4).

\subsection{Thermoelectric performance of $\mathrm{TiS}_{2}(\mathrm{HA})_{x}$ thin films}

Thermoelectric properties of $\mathrm{TiS}_{2}(\mathrm{HA})_{x}$ are presented on figure 6 . TE properties are analyzed for different quantities of intercalated HA ranging from $10 \mathrm{mg}$ up to $170 \mathrm{mg}$ for a fixed mass of $20 \mathrm{mg}$ of $\mathrm{TiS}_{2}$.

In figure 6 (a), electrical conductivity increases rapidly from $60 \mathrm{mg}$ of intercalated HA and reaches a plateau between $80 \mathrm{mg}$ and $110 \mathrm{mg}$, where the average value of electrical conductivity reaches $422 \pm$ $80 \mathrm{Scm}^{-1}$. The intercalated organic component reacts with the inorganic layers of $\mathrm{TiS}_{2}$ and a transfer of electrons occurs from molecules of $\mathrm{HA}$ (nitrogen atoms) to empty $3 \mathrm{~d}$ orbitals of $\mathrm{TiS}_{2}$, thus partially 
reducing $\mathrm{Ti}^{3+}$ [12]. It is a redox process between layers of $\mathrm{TiS}_{2}$ and intercalated molecules of $\mathrm{HA}$ that act as electron donors. Above $110 \mathrm{mg}$ of added HA, the electrical conductivity progressively decreases; it is possible that the excess HA pins the mobility of charge carriers, resulting in lower electrical conductivities.

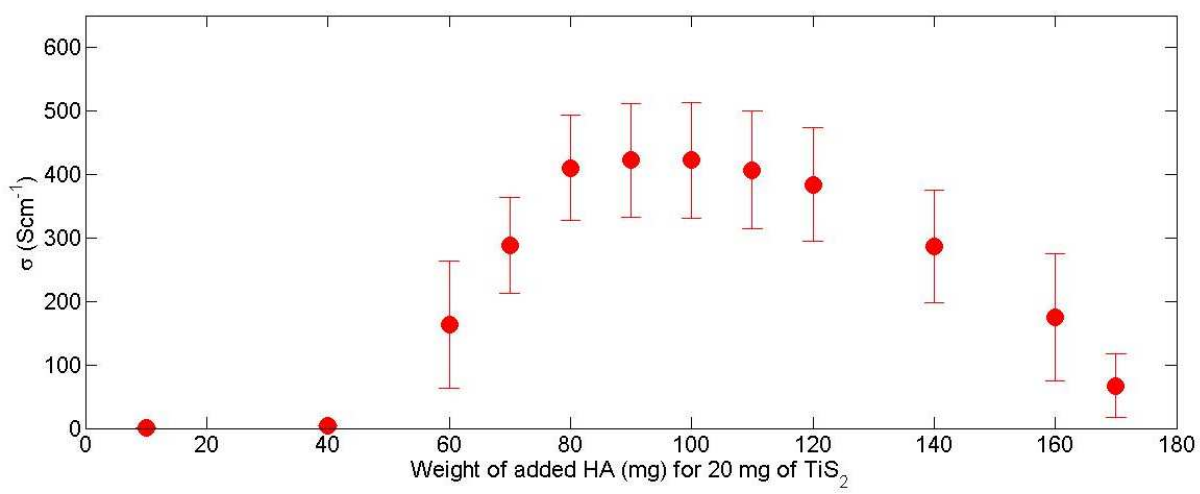

(a)

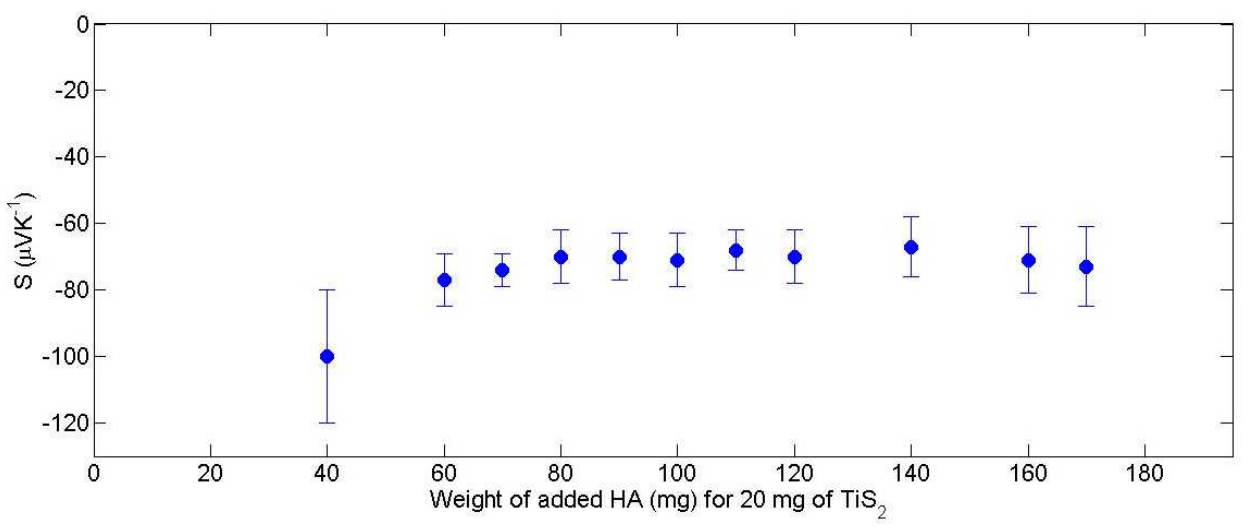

(b)

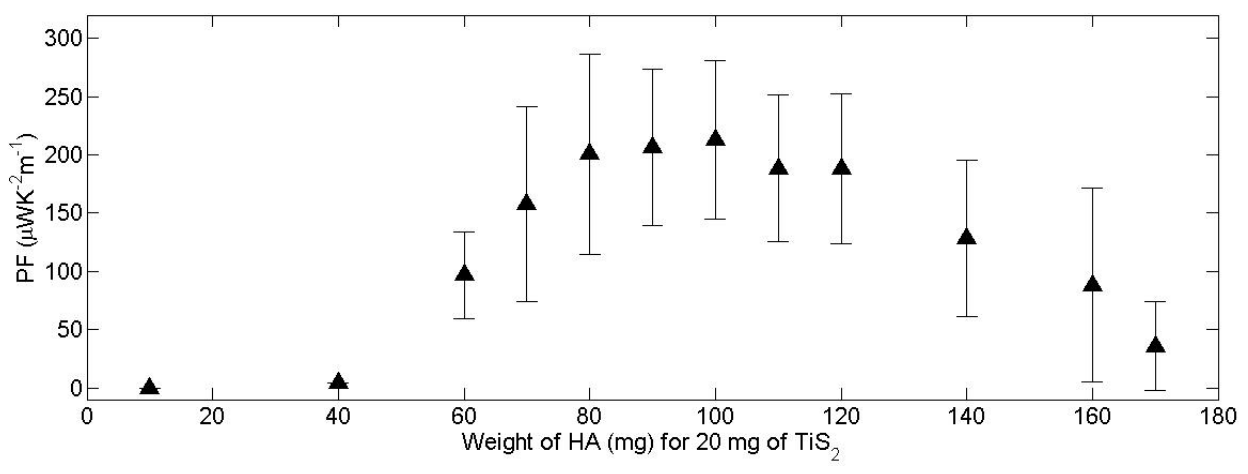

(c) 


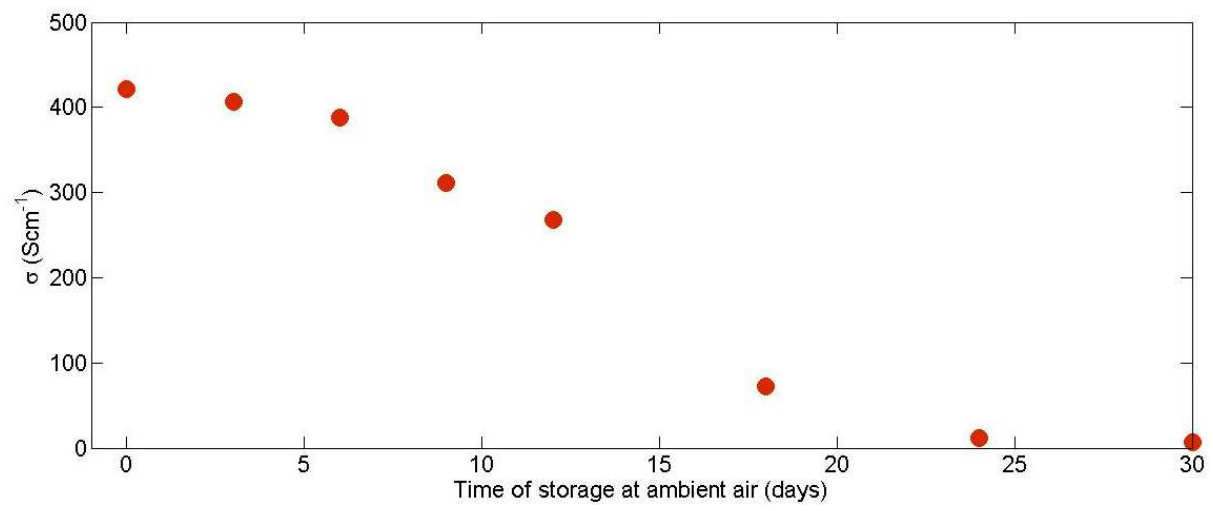

Figure 6. Thermoelectric performance of $\mathrm{TiS}_{2}(\mathrm{HA})_{\mathrm{x}}$ in function of intercalated $\mathrm{HA}$ (in $\mathrm{mg}$ ) for $20 \mathrm{mg}$ of $\mathrm{TiS}_{2} .72$ mg of HA equates to 1:4 molar ratio. (a) Electrical conductivity, (b) Seebeck coefficient, (c) Power Factor and (d) evolution of electrical conductivity of $\mathrm{TiS}_{2}(\mathrm{HA})_{x}$ with exposure time to ambient air.

Furthermore, the negative sign of the Seebeck coefficient confirms the n-type character of electronic transport in the material (figure 6 (b)). Consequently, with the increase of the charge carrier concentration, the absolute values of the Seebeck coefficient decrease slightly from $-101 \pm 20 \mu \mathrm{VK}^{-1}$ (at $40 \mathrm{mg}$ of $\mathrm{HA}$ ) to $-70 \pm 7 \mu \mathrm{VK}^{-1}$ (at $80 \mathrm{mg}$ of $\mathrm{HA}$ ). However, the Seebeck coefficient remains constant at higher ratios of HA. This behavior suggests that intercalating higher quantities of HA (higher than a molar ratio of $1 / 4$ ) does not add more charge carriers. Otherwise, the thermopower would continue to decrease. This behavior could suggest an influence on the morphology and the autoassembly process of $\mathrm{TiS}_{2}(\mathrm{HA})_{x}$ films [4], [6], [9], [11].

Finally, the Power Factor evolution for different quantities of intercalated HA molecules is traced on figure 6 (c). A maximum power factor of $207 \pm 81 \mu \mathrm{WK}^{-1} \mathrm{~m}^{-2}$ is reached at the range of $80-110 \mathrm{mg}$ of intercalated $\mathrm{HA}$ for $20 \mathrm{mg}$ of $\mathrm{TiS}_{2}$.

Optimal thermoelectric performance of $\mathrm{TiS}_{2}(\mathrm{HA})_{x}$ is reported in table 1 (the value of thermal conductivity used in this study is taken from literature [15]). Both $S$ and $\sigma$ of the resulting superlattice are in good agreement with previous studies [15]. A ZT of about $0.08 \pm 0.06$ at an ambient temperature has been reached, which is in a good spot considering the current state-of-the-art $\mathrm{n}$ type organic and hybrid materials.

Table 1. Thermoelectric performance and synthesis conditions of $\mathrm{TiS}_{2}(\mathrm{HA})_{\mathrm{x}}$.

\begin{tabular}{|c|c|c|c|}
\hline $\begin{array}{l}\text { Parameter } \\
\text { (@300K) }\end{array}$ & Value & \multicolumn{2}{|c|}{$\begin{array}{l}\text { Optimal synthesis conditions } \\
\text { (for } 20 \mathrm{mg} \mathrm{TiS} \text { ) }\end{array}$} \\
\hline$\sigma$ & $422 \pm 80 \mathrm{Scm}^{-1}$ & Mass ratio $\left(\mathrm{TiS}_{2}: \mathrm{HA}\right)$ & $0.18-0.25$ \\
\hline $\mathrm{S}$ & $-70 \pm 7 \mu \mathrm{VK}^{-1}$ & Solvent & $3 \mathrm{ml} \mathrm{NMF}$ \\
\hline $\begin{array}{l}\mathrm{K} / / \\
\text { (planar) [15] }\end{array}$ & $0.43 \mathrm{Wm}^{-1} \mathrm{~K}^{-1}$ & Exfoliation & Ultrasonic bath, $30-60 \mathrm{~min}$ \\
\hline $\mathrm{PF}$ & $207 \pm 81 \mu \mathrm{WK}^{-2} \mathrm{~m}^{-1}$ & Centrifugation & $3000 \mathrm{RPM}, 30 \mathrm{~min}$ \\
\hline $\mathrm{ZT}$ & $0.08 \pm 0.06$ & Annealing & $100-115^{\circ} \mathrm{C}, 60 \mathrm{~min}$ \\
\hline
\end{tabular}


To measure the stability of this material at ambient conditions, four samples of $\mathrm{TiS}_{2}(\mathrm{HA})_{x}$ thin films were exposed to ambient air at room temperature for a month and their thermoelectric properties were continuously evaluated. The evolution of the mean electrical conductivity of all $4 \mathrm{TiS}_{2}(\mathrm{HA})_{x}$ samples in function of time of exposure to ambient air is presented on figure 6 (d), and it decreases progressively with time. After about 15 days of exposure to ambient air the electrical conductivity is halved; it reaches $6 \mathrm{Scm}^{-1}$ after 25 days. Thus, $\mathrm{TiS}_{2}(\mathrm{HA})_{x}$ is instable in ambient conditions and further research is required to understand and possibly solve the mechanisms of degradation in this material. Otherwise, one possible solution could be the encapsulation of thermoelectric devices based on $\mathrm{TiS}_{2}(\mathrm{HA})_{x}$ as the $\mathrm{n}$ type component.

\subsection{Printing of $\mathrm{TiS}_{2}\left[(\mathrm{HA})_{\mathrm{x}}(\mathrm{NMF})_{\mathrm{y}}\right]$ ink}

Formulation of materials into ink is a crucial part in development of a fabrication process based on inkjet printing. A successful printing fabrication process depends on numerous factors such as the rheology of the material, size of the particles, ink-matter (i.e. substrate) interaction and waveform properties of the jetting electric pulse. In the end, the desired pattern should be successfully reproduced and the active layers functional. The measured viscosity of $\mathrm{TiS}_{2}\left[(\mathrm{HA})_{x}(\mathrm{NMF})_{\mathrm{y}}\right]$ is about 4 $\mathrm{mPa} \cdot \mathrm{s}$ which is within the allowed range of the DIMATIX printer. Measured surface tension is of 37 $\mathrm{mNm}^{-1}$ (figure $7(\mathrm{a})$ ), which is equivalent to the NMF solvent. Thus, thanks to the properties of NMF, the $\mathrm{TiS}_{2}\left[(\mathrm{HA})_{x}(\mathrm{NMF})_{\mathrm{y}}\right]$ dispersion is by default ejectable and does not require major rheological adjustments.

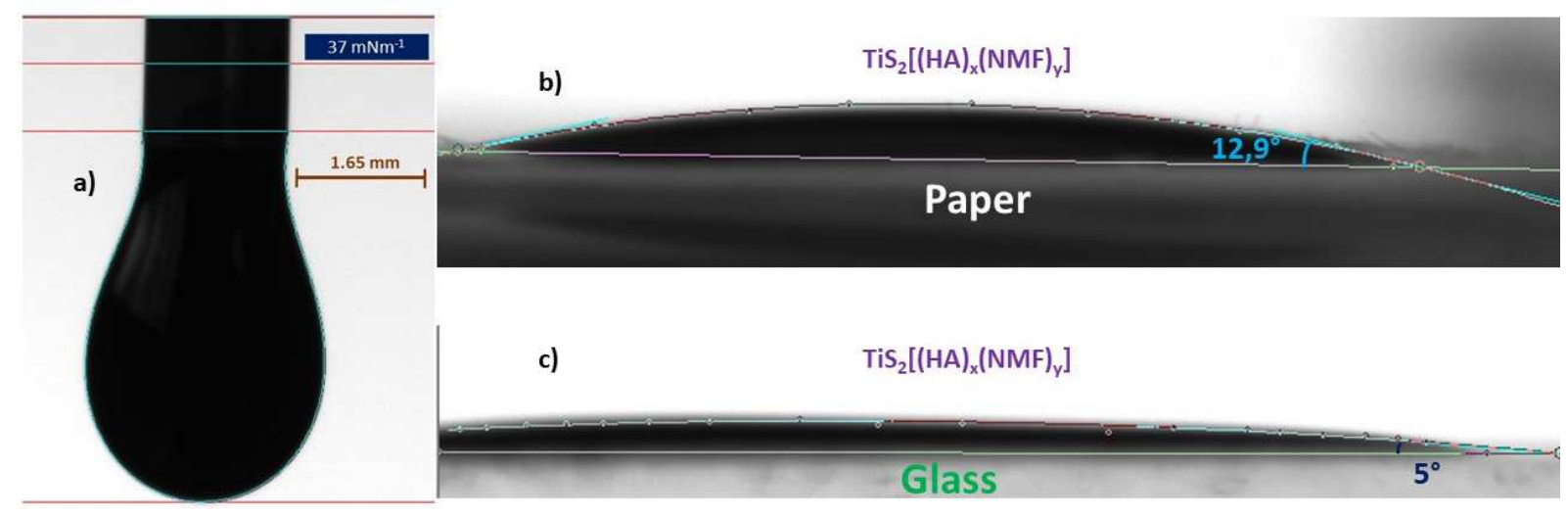

Figure 7. (a) Suspended drop of $\mathrm{TiS}_{2}\left[(\mathrm{HA})_{x}(\mathrm{NMF})_{\mathrm{y}}\right]$ in air. Contact angle of $\mathrm{TiS}_{2}\left[(\mathrm{HA})_{\mathrm{x}}(\mathrm{NMF})_{\mathrm{y}}\right]$ drop deposited on paper (b) and glass (c).

$\mathrm{TiS}_{2}\left[(\mathrm{HA})_{x}(\mathrm{NMF})_{\mathrm{y}}\right]$ does not require any particular filtration as suspended particles are of nanometric scale, which is well inferior in size to printhead nozzle diameter $(21.5 \mu \mathrm{m})$. However, with time, the particles have a tendency to agglomerate into larger particles which could hinder the printing process by blocking the nozzle. A regular treatment of the dispersion in an ultrasonic bath seems to redistribute particles in the solvent and help to avoid nozzle blocking.

Profiles of drops of $\mathrm{TiS}_{2}\left[(\mathrm{HA})_{\times}(\mathrm{NMF})_{\mathrm{y}}\right]$ deposited on paper substrate and glass substrate are presented on figures 7 (b) and 7 (c). In both cases $\mathrm{TiS}_{2}\left[(\mathrm{HA})_{x}(\mathrm{NMF})_{\mathrm{y}}\right]$ shows a high wettability on both substrates. Theoretically we would expect a badly printed (overspread) pattern as the contact angles showed to 
be low on both substrates $\left(12.9^{\circ}\right.$ on paper and $5^{\circ}$ on glass). Usually the aimed contact angle should be superior to $40^{\circ}$ for a correct pattern reproduction [22].

However, the results were different when printing on paper as shown in figure 8 (a) (photography of a printed $\mathrm{TiS}_{2}(\mathrm{HA})_{\times}$sample on paper patterned in a series of $3 \mathrm{~mm}$ large and $6 \mathrm{~mm}$ long rectangles). Indeed, the printed pattern matched very well the desired pattern, although some remains of NMF solvent spread across the substrate were visible. This suggests that particles of $\mathrm{TiS}_{2}(\mathrm{HA})_{\times}$are embedded in the pores in paper during drop deposition. On the other hand, the solvent spreads across the substrate surface because of its high wettability. While spreading, the solvent apparently does not carry with it the particles of $\mathrm{TiS}_{2}(\mathrm{HA})_{x}$ as they are stuck in the pores. This allows a relatively precise reproduction of the desired pattern. This was not the case in glass substrates, as the ink overspread across the substrate along with particles.
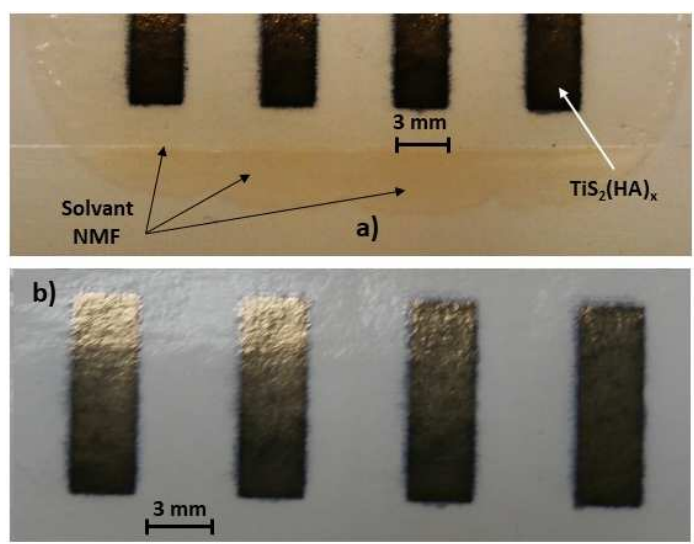

Figure 8. Photography of printed $\mathrm{TiS}_{2}(\mathrm{HA})_{x}$, the NMF solvent overspreads across the surface of the substrate, yet the printed pattern is correct (a). Photography of printed $\mathrm{TiS}_{2}(\mathrm{HA})_{\times}$on paper after annealing (b).

Table 2. Performance of $\mathrm{TiS}_{2}(\mathrm{HA})_{x}$ printed on glass and paper or dropcasted on glass; PEDOT:PSS (PJET 700) printed on paper is also represented.

\begin{tabular}{|c|c|c|c|c|}
\hline $\begin{array}{l}\text { Parameter } \\
\text { (@300K) }\end{array}$ & $\begin{array}{c}\mathrm{TiS}_{2}(\mathrm{HA})_{\mathrm{x}} \\
\\
\begin{array}{c}\text { Dropcasted on } \\
\text { glass }\end{array}\end{array}$ & $\begin{array}{c}\mathrm{TiS}_{2}(\mathrm{HA})_{x} \\
\text { Printed on Glass }\end{array}$ & $\begin{array}{c}\mathrm{TiS}_{2}(\mathrm{HA})_{\mathrm{x}} \\
\text { Printed on paper }\end{array}$ & $\begin{array}{c}\text { PEDOT:PSS } \\
\text { Printed on paper }\end{array}$ \\
\hline$\sigma\left(\mathrm{Scm}^{-1}\right)$ & $422 \pm 80$ & $430 \pm 68$ & $428 \pm 40$ & $650 \pm 50$ \\
\hline $\mathrm{S}\left(\mu \mathrm{VK}^{-1}\right)$ & $-70 \pm 7$ & $-70 \pm 6$ & $-70 \pm 6$ & $17 \pm 6$ \\
\hline $\mathrm{PF}\left(\mu \mathrm{W} \mathrm{K}^{-2} \mathrm{~m}^{-1}\right)$ & $207 \pm 81$ & $211 \pm 70$ & $210 \pm 56$ & $19 \pm 4$ \\
\hline
\end{tabular}

Printed $\mathrm{TiS}_{2}(\mathrm{HA})_{x}$, whether on glass or paper, showed similar thermoelectric performance compared to dropcasted films (table 2).

For $\mathrm{TiS}_{2}(\mathrm{HA})_{x}$ nanoparticles to autoassemble into films, deposited samples should be thermally annealed in a controlled inert environment. Fortunately, the NMF is a liquid with high boiling point (near $180^{\circ} \mathrm{C}$ [23]) which allows $\mathrm{TiS}_{2}\left[(\mathrm{HA})_{x}(\mathrm{NMF})_{\mathrm{y}}\right]$ to remain in its liquid phase during the printing process. After deposition, the substrate with the printed $\mathrm{TiS}_{2}\left[(\mathrm{HA})_{\times}(\mathrm{NMF})_{\mathrm{y}}\right]$ pattern is placed in a 
glovebox for a thermal annealing at $110^{\circ} \mathrm{C}$ under inert conditions (nitrogen); thus, films of $\mathrm{TiS}_{2}(\mathrm{HA})_{x}$ are formed.

In the end, the results of printed $\mathrm{TiS}_{2}\left[(\mathrm{HA})_{\times}(\mathrm{NMF})_{\mathrm{y}}\right]$ on paper are satisfactory: the printed pattern matches the desired pattern (figure 8 (b)). and thermoelectric performance was intact after printing (table 2).

\subsection{Device performance}

Measured thermoelectric performance of printed $\pi$-shaped devices is presented in Table 3. In this work, a slightly asymmetrical structure with a slightly larger n-type leg has been adopted; the intention is to balance the internal resistances of both legs by means of geometrical design. Indeed, as the ntype material is slightly less conductive than the p-type component $\left(422 \mathrm{Scm}^{-1}\right.$ vs $\left.650 \mathrm{Scm}^{-1}\right)$, it is possible to diminish the internal resistance of the $n$-type leg by enlarging it. Considering the ratio between electrical conductivities of both materials which is near 1.5, the n-type leg must be approximately 1.5 larger than the $p$-type leg.

In this study, the organic thermoelectric device is of the classic flat-plate, " $\pi$ "-shaped architecture composed of 7 thermocouples with p-type (PEDOT:PSS) leg width of $1 \mathrm{~mm}$ and the n-type $\left(\mathrm{TiS}_{2}(\mathrm{HA})_{\mathrm{x}}\right)$ leg width of $1.57 \mathrm{~mm}$. The total width is of the device is $32 \mathrm{~mm}$ to match the heat source, which is a square-shaped $4 \times 4 \mathrm{~cm}^{2}$ Peltier module. The active thermoelectric films (i. e. not counting the thickness of the paper substrate) are about $4 \mu \mathrm{m}$ thick. The legs are separated by blank gaps of $1 \mathrm{~mm}$ wide to avoid potential short circuits between active layers; thermoelectric legs are electrically connected in series with printed silver electrodes.

In this study, the thermoelectric device operated under an applied temperature difference of $20 \mathrm{~K}$. The choice of such a moderate temperature difference has been made for several reasons : the first one is the need to maintain thermoelectric parameters constant under applied temperature; the second was the consideration for possible applications of the printed flexible devices in e-textiles, body-heat harvesters and human-machine interfacing; and the third reason for a moderate near ambient temperature gradient was to avoid destruction of organic materials and of the paper substrate which can occur with high temperatures [24]-[28].

Thus, thermoelectric generators in this study were designed for a temperature difference of $20 \mathrm{~K}(\Delta \mathrm{T}=$ 20K). The leg length is of $4 \mathrm{~mm}$ to match the minimum length required to build and maintain the desired temperature difference $(\Delta T=20 \mathrm{~K})$. A study of the evolution of the temperature gradient with leg length has been made using numerical simulations. In the simulation model, $\Delta T$ is established by applying heat on the bottom electrodes of the device, and the ambient air, which acts as a heat dissipator, interacts with the rest of the surface of the device [18].

Table 3. Experimental and numerical results of the generator based on PEDOT:PSS and $\mathrm{TiS}_{2}(\mathrm{HA})_{\mathrm{x}}$.

\begin{tabular}{|c|c|c|}
\hline Parameter & $\begin{array}{c}\text { Numerically calculated } \\
\text { (Contact resistance } \\
\text { accounted) }\end{array}$ & $\begin{array}{c}\text { Experimentally } \\
\text { measured }\end{array}$ \\
\hline $\mathrm{V}_{\mathrm{OC}}$ & 12.18 & 11.5 \\
\hline
\end{tabular}




\begin{tabular}{|c|c|c|}
\hline$(\mathrm{mV})$ & & \\
\hline $\mathrm{I}_{\mathrm{sc}}$ & 8.2 & 7.8 \\
$(\mu \mathrm{A})$ & - & \\
\hline $\mathrm{R}_{\mathrm{i}}$ & & 1474 \\
$(\Omega)$ & 25 & \\
\hline $\mathrm{P}_{\max }$ & & 22.5 \\
$(\mathrm{nW})$ & & \\
\hline
\end{tabular}

Table 4. Geometrical parameters of the printed OTEG.

\begin{tabular}{|c|c|c|c|c|c|c|}
\hline $\begin{array}{c}\text { Number of } \\
\text { TCs }\end{array}$ & $\begin{array}{c}\text { Leg } \\
\text { length }\end{array}$ & $\begin{array}{c}\text { Leg width } \\
(\mathrm{p})\end{array}$ & $\begin{array}{c}\text { Leg width } \\
(\mathrm{n})\end{array}$ & $\begin{array}{c}\text { Leg } \\
\text { thickness }\end{array}$ & $\begin{array}{c}\text { Total } \\
\text { OTEG area }\end{array}$ & Fill Factor \\
\hline 7 & $4 \mathrm{~mm}$ & $1 \mathrm{~mm}$ & $1.57 \mathrm{~mm}$ & $4 \mu \mathrm{m}$ & $128 \mathrm{~mm}^{2}$ & $75 \%$ \\
\hline
\end{tabular}

To theoretically evaluate TE performance of the device, a series of numerical simulations and calculations were made and compared to the experimental results. Numerical simulations were produced on a 3D-finite element analysis multiphysics software with coupled physical problems (here thermal and electrical flows). The details on the methodology of calculations and simulations can be found in Ferhat et al. (2017) [18]. The values of the expected numerical performance as well as the experimental results are reported in table 3.

First, we can observe a good agreement between calculated open circuit voltage $V_{\text {oc }}(12.18 \mathrm{mV})$ with the experimentally obtained $V_{O c}(11.5 \mathrm{mV})$. For a fair comparison, measured contact electrical resistances have been accounted in the numerical calculations. Both numerically obtained $I_{s c}$ and $R_{i}$ showed to be close to the experimentally measured results. The maximum power output $P_{\max }$ is the power delivered to a load resistance $R_{L}$ connected to the device and is equal to devices internal resistance $\left(R_{L}=R_{i}\right)$. Experimentally, the thermoelectric generator produced a power output $P_{\max }$ near $22.5 \mathrm{nW}$ at $(\Delta \mathrm{T}=20 \mathrm{~K})$. There is a low disparity between the experimentally measured output parameters and the numerically calculated ones. However, the low disparity is well within the margin of measurement error and could mostly be attributed to the slight loss of heat at the thermal contacts. This shows the relative accuracy of the simulation model [18] with respect to experimental results when contact resistances are accounted for.

If we consider the heat flux applied to the cross-sectional area of the device, as it is the case in a rolled structure placed on top of a heat source, the power output of the device reaches a power density of $17.6 \mu \mathrm{Wcm}^{-2}$ at $\Delta \mathrm{T}=20 \mathrm{~K}$. In comparison to other reported high power flexible TEGs, Kim et al. (2018) fabricated a flexible TEG for wearable applications based on traditional inorganic $\mathrm{Bi}_{0.5} \mathrm{Sb}_{1.5} \mathrm{Te}_{3}$ (p-type) and $\mathrm{Bi}_{2} \mathrm{Se}_{0.3} \mathrm{Te}_{2.7}$ (n-type) which yielded a power density of $2.28 \mu \mathrm{Wcm}^{-2}$ with an applied near ambient temperature ( $\Delta \mathrm{T}$ around $12 \mathrm{~K}$ ) [29]. Fang et al. (2017) produced a large 288 legged flexible TEG by screen printing PEDOT:PSS and nickel on Kapton substrate; they obtained a power density reaching 46 $\mu \mathrm{W}$ at an applied temperature difference of $65 \mathrm{~K}[30]$. There is, however, no standard way to measure the quality of thin flexible devices as many parameters and variables play important roles (such as applied temperature, size and structure of the devices, number of legs, fabrication process...). This 
complicates direct comparisons with other devices. Considering the size of the device and the applied near-ambient temperature, the output power yielded by the printed device in this study is amongst high-performance state-of-the-art devices, in addition to be fabricated with a cutting-edge inkjet printing technology. The device could be used to power sensors and microelectromechanical systems that can operate in the microwatt range.

\subsection{Bending tests on OTEG devices and power output variations upon bending}

The inward bending (figure 9) of the printed thermoelectric devices was done by attaching them to two ceramic pieces of different radii $(1.6 \mathrm{~cm}$ and $1 \mathrm{~cm})$. The device was also attached directly to the heat source (Peltier module) unbent (infinite radius of curvature). The power output has remained relatively constant under inward bending with a very slight decrease from $22.5 \mathrm{nW}$ (unbent) to 22.1 $\mathrm{nW}$ when bent at $1 \mathrm{~cm}$ of radius of curvature.
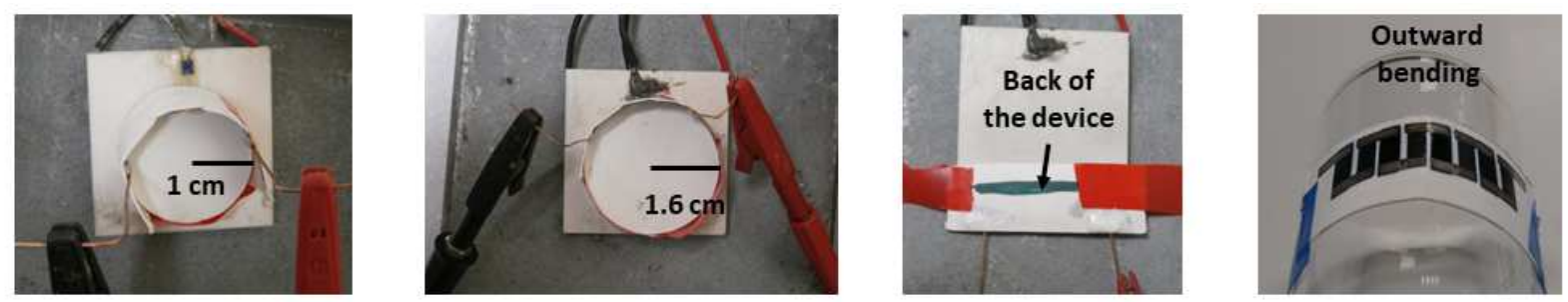

Figure 9. Inward and outward bending of the thermoelectric device printed on paper.

OTEGs subjected to outward bending have also been studied. For this purpose, the variation of the internal resistance has been measured as a function of the outward radius of curvature; the results are presented in figure 10. There is a slight increase of $R_{i}$ from $1474 \Omega$ (no curvature) to $1517 \Omega$ with outward bending up to $1.2 \mathrm{~cm}$ of radius of curvature (figure 10). This slight increase in internal resistance should not affect significantly the performance of generators.

The devices showed a reversibility of performance. After a gentle (uniform and regular bending with an estimated angular velocity of $<0.4 \mathrm{rad} \mathrm{s}^{-1}$ ) inward or outward bending and a straightening out, the performance reversed to the original value of the unbent device.

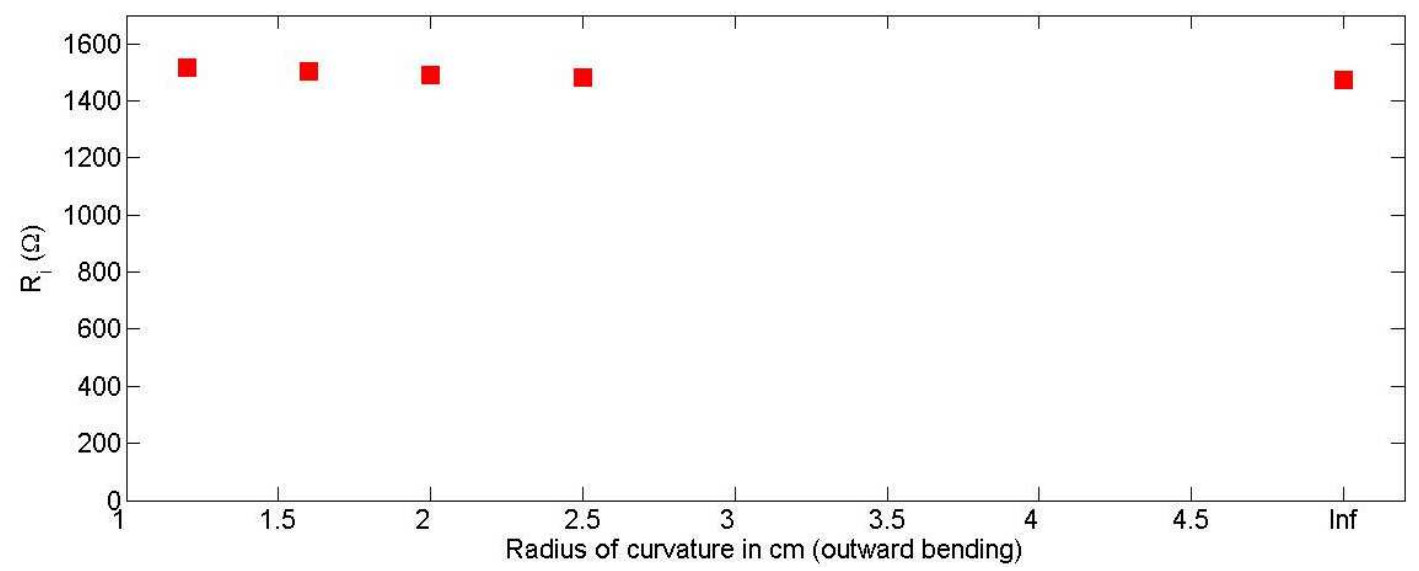

Figure 10. Evolution of the internal resistance with radius of curvature of outwardly bent generator printed on paper. 
We can conclude that the loss of performance of the OTEG printed on paper under mechanical stress and bending is negligible, which is an important property for a flexible thermoelectric device.

\section{Conclusion}

Flexible thermoelectric devices have been successfully designed and entirely fabricated using inkjet printing technology. Both p-type (PEDOT:PSS) and n-type $\left(\mathrm{TiS}_{2}(\mathrm{HA})_{\mathrm{x}}\right)$ organic and hybrid materials showed excellent thermoelectric properties due to their large reproductible electrical conductivities, approaching a ZT of $0.08 \pm 0.06$ for the n-type component, which corresponds to the state-of-the-art for this class of materials. However, further efforts must be made in improving the stability of transport properties of the n-type $\mathrm{TiS}_{2}(\mathrm{HA})_{x}$ material in ambient conditions. The adaptation of the n-type thermoelectric nanocomposite $\mathrm{TiS}_{2}(\mathrm{HA})_{x}$ to inkjet printing deposition was a success, particularly when printing on paper substrate, where the desired pattern was correctly reproduced; thermoelectric performance of the printed thermoelectric materials remained intact after the printing process. Thus, an OTEG has been printed, composed of seven thermocouples patterned in the classic $\pi$-shaped structure with a slightly asymmetrical structure to minimize resistive losses. The thermoelectric performance of the generator was evaluated numerically and measured experimentally; the results showed a good correlation between expected numerical values and experimental ones. A power output of $\mathrm{P}_{\max }=22.5 \mathrm{nW}$ was produced by a small device of total area near $128 \mathrm{~mm}^{2}$ at a near-ambient gradient of temperature $\Delta T=20 \mathrm{~K}$. If we consider the heat flux applied to the cross-sectional area of the device as it is the case in a rolled structure placed on top of the heat source, the power output of the device reaches a power density of $17.6 \mu \mathrm{Wcm}^{-2}$ at $\Delta \mathrm{T}=20 \mathrm{~K}$. In addition to a convenient fabrication process based on inkjet printing technology, the power output of the reported device is at a competitive level relative to state-of-the-art thin flexible devices operating at a similar temperature range.

\section{Acknowledgement}

The authors acknowledge Institut des sciences de l'ingénierie et des systèmes (INSIS) of Centre national de la recherche scientifique (CNRS) and Électricité de France (EDF).

\section{References.}

[1] A. Raj et D. Steingart, "Review-Power Sources for the Internet of Things ", J. Electrochem. Soc., vol. 165, nº 8, p. B3130-B3136, janv. 2018.

[2] H. J. Goldsmid, "Review of Thermoelectric Materials », in Introduction to Thermoelectricity, Springer, Berlin, Heidelberg, 2016, p. 153-195.

[3] O. Bubnova et X. Crispin, "Towards polymer-based organic thermoelectric generators ", Energy Environ. Sci., vol. 5, n 11, p. 9345-9362, oct. 2012.

[4] Q. Zhang, Y. Sun, W. Xu, et D. Zhu, « Organic Thermoelectric Materials: Emerging Green Energy Materials Converting Heat to Electricity Directly and Efficiently ", Adv. Mater., vol. 26, $n^{\circ} 40$, p. 6829-6851, oct. 2014.

[5] R. Yue et J. Xu, « Poly(3,4-ethylenedioxythiophene) as promising organic thermoelectric materials: A mini-review », Synth. Met., vol. 162, n 11, p. 912-917, juill. 2012. 
[6] N. Toshima, "Conductive polymers as a new type of thermoelectric material ", Macromol. Symp., vol. 186, nº 1, p. 81-86, août 2002.

[7] S. LeBlanc, « Thermoelectric generators: Linking material properties and systems engineering for waste heat recovery applications ", Sustain. Mater. Technol., vol. 1-2, p. 26-35, déc. 2014.

[8] B. T. McGrail, A. Sehirlioglu, et E. Pentzer, «Polymer Composites for Thermoelectric Applications ", Angew. Chem. Int. Ed., vol. 54, n 6, p. 1710-1723, févr. 2015.

[9] O. Bubnova, Z. U. Khan, H. Wang, S. Braun, D. R. Evans, M. Fabretto, P. Hojati-Talemi, D. Dagnelund, J.-B. Arlin, Y. H. Geerts, S. Desbief, D. W. Breiby, J. W. Andreasen, R. Lazzaroni, W. M. Chen, I. Zozoulenko, M. FahIman, P. J. Murphy, M. Berggren, et X. Crispin, « Semi-metallic polymers », Nat. Mater., vol. 13, n² 2, p. 190-194, févr. 2014.

[10] Y. Du, S. Z. Shen, K. Cai, et P. S. Casey, "Research progress on polymer-inorganic thermoelectric nanocomposite materials », Prog. Polym. Sci., vol. 37, nº 6, p. 820-841, juin 2012.

[11] H. Yoshino, G. C. Papavassiliou, et K. Murata, " Low-Dimensional organic conductors as thermoelectric materials ", J. Therm. Anal. Calorim., vol. 92, n² 2, p. 457-460, mai 2008.

[12] C. Wan, X. Gu, F. Dang, T. Itoh, Y. Wang, H. Sasaki, M. Kondo, K. Koga, K. Yabuki, G. J. Snyder, R. Yang, et K. Koumoto, " Flexible n-type thermoelectric materials by organic intercalation of layered transition metal dichalcogenide TiS2 », Nat. Mater., vol. 14, nº 6, p. 622-627, juin 2015.

[13] Y. Sun, P. Sheng, C. Di, F. Jiao, W. Xu, D. Qiu, et D. Zhu, « Organic thermoelectric materials and devices based on p-and n-type poly(metal 1,1,2,2-ethenetetrathiolate)s ", Adv. Mater. Deerfield Beach Fla, vol. 24, n 7, p. 932-937, févr. 2012.

[14] Y. Nonoguchi, K. Ohashi, R. Kanazawa, K. Ashiba, K. Hata, T. Nakagawa, C. Adachi, T. Tanase, et T. Kawai, «Systematic Conversion of Single Walled Carbon Nanotubes into n-type Thermoelectric Materials by Molecular Dopants ", Sci. Rep., vol. 3, nov. 2013.

[15] C. Wan, R. Tian, A. B. Azizi, Y. Huang, Q. Wei, R. Sasai, S. Wasusate, T. Ishida, et K. Koumoto, "Flexible thermoelectric foil for wearable energy harvesting ", Nano Energy, vol. 30, p. 840-845, déc. 2016.

[16] G.-H. Kim, L. Shao, K. Zhang, et K. P. Pipe, « Engineered doping of organic semiconductors for enhanced thermoelectric efficiency ", Nat. Mater., vol. 12, nº 8, p. 719-723, août 2013.

[17] E. J. Bae, Y. H. Kang, K.-S. Jang, et S. Y. Cho, « Enhancement of Thermoelectric Properties of PEDOT:PSS and Tellurium-PEDOT:PSS Hybrid Composites by Simple Chemical Treatment ", Sci. Rep., vol. 6, p. srep18805, janv. 2016.

[18] S. Ferhat, C. Domain, J. Vidal, D. Noël, B. Ratier, et B. Lucas, « Organic thermoelectric devices based on a stable n-type nanocomposite printed on paper ", Sustain. Energy Fuels, vol. 2, n 1, p. 199-208, déc. 2017.

[19] Q. Wei, M. Mukaida, K. Kirihara, Y. Naitoh, et T. Ishida, « Polymer thermoelectric modules screen-printed on paper ", RSC Adv., vol. 4, n 54, p. 28802-28806, juin 2014. 
[20] R. R. Søndergaard, M. Hösel, N. Espinosa, M. Jørgensen, et F. C. Krebs, « Practical evaluation of organic polymer thermoelectrics by large-area R2R processing on flexible substrates ", Energy Sci. Eng., vol. 1, n² 2, p. 81-88, sept. 2013.

[21] C. Wan, R. Tian, A. B. Azizi, Y. Huang, Q. Wei, R. Sasai, S. Wasusate, T. Ishida, et K. Koumoto, "Flexible thermoelectric foil for wearable energy harvesting ", Nano Energy, vol. 30, n Supplement C, p. 840-845, déc. 2016.

[22] R. A. Street, W. S. Wong, S. E. Ready, M. L. Chabinyc, A. C. Arias, S. Limb, A. Salleo, et R. Lujan, « Jet printing flexible displays », Mater. Today, vol. 9, nº 4, p. 32-37, avr. 2006.

[23] « N-METHYLFORMAMIDE | CAMEO Chemicals | NOAA ». [En ligne]. Disponible sur: https://cameochemicals.noaa.gov/chemical/20654.

[24] B. Friedel, P. E. Keivanidis, T. J. K. Brenner, A. Abrusci, C. R. McNeill, R. H. Friend, et N. C. Greenham, " Effects of Layer Thickness and Annealing of PEDOT:PSS Layers in Organic Photodetectors ", Macromolecules, vol. 42, nº 17, p. 6741-6747, sept. 2009.

[25] J. Livage, « Vanadium pentoxide gels », Chem. Mater., vol. 3, n 4, p. 578-593, juill. 1991.

[26] E. G. Vitoratos, S. A. Sakkopoulos, E. Dalas, N. Paliatsas, D. Karageorgopoulos, F. Petraki, S. Kennou, et S. A. Choulis, « Thermal degradation mechanisms of PEDOT:PSS », 2009.

[27] H. Shi, C. Liu, Q. Jiang, et J. Xu, « Effective Approaches to Improve the Electrical Conductivity of PEDOT:PSS: A Review », Adv. Electron. Mater., vol. 1, n 4, p. 1500017, avr. 2015.

[28] B. M. Reddy, S. Mehdi, et E. P. Reddy, « Dispersion and thermal stability of vanadium oxide catalysts supported on titania-silica mixed oxide ", Catal. Lett., vol. 20, n 3-4, p. 317-327, sept. 1993.

[29] C. S. Kim, G. S. Lee, H. Choi, Y. J. Kim, H. M. Yang, S. H. Lim, S.-G. Lee, et B. J. Cho, « Structural design of a flexible thermoelectric power generator for wearable applications ", Appl. Energy, vol. 214, p. 131-138, mars 2018.

[30] H. Fang, B. C. Popere, E. M. Thomas, C.-K. Mai, W. B. Chang, G. C. Bazan, M. L. Chabinyc, et R. A. Segalman, « Large-scale integration of flexible materials into rolled and corrugated thermoelectric modules ", J. Appl. Polym. Sci., vol. 134, nº 3, 2017. 


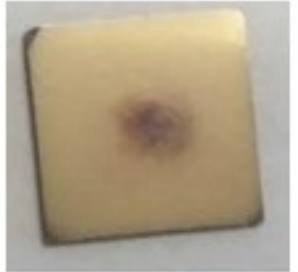

$\mathrm{TiS}_{2}(\mathrm{HA})_{\mathrm{x}}$

$\mathrm{TiS}_{2}(\mathrm{HA})_{\mathrm{x}}$ $\mathrm{TiS}_{2}(\mathrm{HA})_{\mathrm{x}}$
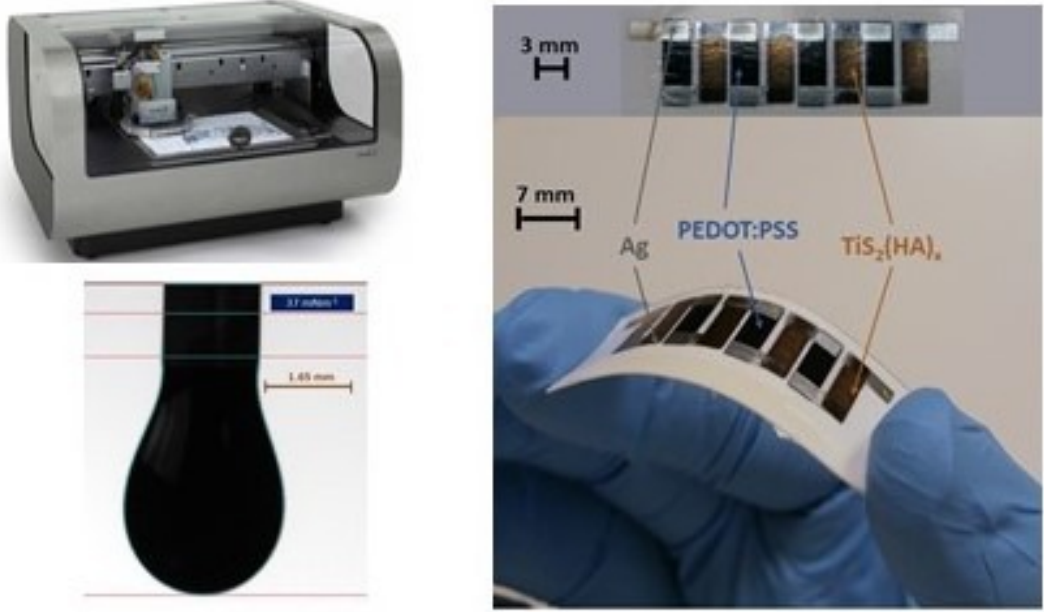

$\mathrm{TiS}_{2}(\mathrm{HA})_{\mathrm{x}}$ nanocomposite optimized for thermoelectric generation, adapted for the first time to printing technology and used for patterning a device. 